Tropical Journal of Pharmaceutical Research September 2020; 19 (9): 1911-1917

ISSN: $1596-5996$ (print); 1596-9827 (electronic)

(C) Pharmacotherapy Group, Faculty of Pharmacy, University of Benin, Benin City, 300001 Nigeria.

\title{
Saussurea lappa Clarke extract exhibits potent antioxidant effect and attenuates neuroinflammatory responses in lipopolysaccharide-stimulated microglial cells
}

\author{
Sung-Gyu Lee, Hyun Kang* \\ Department of Medical Laboratory Science, College of Health Science, Dankook University, Cheonan-si, Chungnam 330-714, \\ Republic of Korea
}

*For correspondence: Email: hyunkang2@gmail.com; Tel: +82-41-550-3015

Sent for review: 6 February 2020

Revised accepted: 19 August 2020

\begin{abstract}
Purpose: To investigate the antioxidant and anti-neuroinflammatory potential of Saussurea lappa Clarke (SLC-EA) extract in LPS-stimulated BV-2 microglial cells.

Methods: Cell viability was measured by using the 3-[4,5-dimethylthiazol-2-yl]-2,5-diphenyltetrazolium bromide (MTT) assay while antioxidant activity was evaluated by using the DPPH (1,1-diphenyl-2-picrylhydrazyl) radical scavenging activity. Lipopolysaccharide (LPS) was used to stimulate BV-2 microglia. Griess assay was employed to assess nitric oxide (NO) production. iNOS (inducible NO synthase) expression and TNF- $\alpha$ (tumor necrosis factor-alpha) cytokine production were measured by ELISA (enzyme-linked immunosorbent assay) and immuno blot analysis, respectively.

Results: Pretreatment of $100 \mathrm{mg} / \mathrm{ml}$ of SLC-EA ( $p<0.001)$ was inhibited Nitric Oxide (NO) by $1 \mathrm{ug} / \mathrm{ml}$ of LPS-treated murine BV-2 cells. The expression of iNOS and TNF- $\alpha$ were reduced by SLC-EA concentration dependent manner ( $p<0.001$ at $100 \mathrm{mg} / \mathrm{ml})$. SLC-EA were scavenged 1, 1-diphenyl-2picrylhydrazyl (DPPH) radicals in a dose-dependent manner with an IC50 value of approximately 51.4 $\mu \mathrm{g} / \mathrm{ml}$.

Conclusion: The results indicate that SLC-EA extract exhibits strong antioxidant properties and inhibits excessive pro-inflammatory cytokine due probably to the antioxidant phenolic compounds present in SLC-EA extract. Further work in exploring the in-depth mechanisms of SLC-EA extract in regulating inflammatory signaling pathways in treating neuroinflammatory diseases is necessary.
\end{abstract}

Keywords: Saussurea lappa, Antioxidant, Neuroinflammation, Microglia, TNF-a, iNOS

\begin{abstract}
This is an Open Access article that uses a fund-ing model which does not charge readers or their institutions for access and distributed under the terms of the Creative Commons Attribution License (http://creativecommons.org/licenses/by/4.0) and the Budapest Open Access Initiative (http://www.budapestopenaccessinitiative.org/read), which permit unrestricted use, distribution, and reproduction in any medium, provided the original work is properly credited.

Tropical Journal of Pharmaceutical Research is indexed by Science Citation Index (SciSearch), Scopus, International Pharmaceutical Abstract, Chemical Abstracts, Embase, Index Copernicus, EBSCO, African Index Medicus, JournalSeek, Journal Citation Reports/Science Edition, Directory of Open Access Journals (DOAJ), African Journal Online, Bioline International, Open-J-Gate and Pharmacy Abstracts
\end{abstract}

\section{INTRODUCTION}

Stress related stimulating cell signaling and untimely generating of the cell death pathways involved in the beginning of some neurological diseases [1]. PD (Parkinson's disease), second most common degenerative dementia is a loss of dopaminergic neurons in the substantia nigra important to subsequent deficiency of dopamine in brain [2]. Accumulating indication intensely support the theory of oxidative stress and mitochondrial defect in the pathogenesis of this disease. The major mitochondrial dysfunction 
identified in PD is inhibition of respiratory chain complex I [2-4].

Microglia activation results in consequent release of different pro-inflammatory mediators and free radicals [5]. It was well documented that reduction of pro-inflammatory mediators such as NO (nitric oxide), iNOS (inducible NO synthase), TNF- $\alpha$ (tumor necrosis factor-alpha) and several other inflammatory cytokines in stimulated microglia could reduce the severity of these disorders [6]. LPS (Lipopolysaccharide), found in the outer membrane of Gram-negative bacteria such as Escherichia coli can activate microglia both in vitro and in vivo and releases various proinflammatory and neurotoxic factors. Therefore, LPS-stimulated microglia is a useful in vitro model for rapid screening of several antineuroinflammatory agents [7].

In current times, various herbal plants and their active physiological role have come to highlight and have been accepted for wide-ranging research. These oriental medicines have been confirmed by traditional usage as compared to current trend supplements. The oriental herbal medicines with reliable ethnopharmacological properties have been demonstrated to have neurotrophic and neuroprotective effects, which can be beneficial in preventing various forms of neuronal cell loss in brain including the nigrostriatal degeneration seen in PD $[8,9]$. Many reports have confirmed that medicinal herbbased extracts increase the anti-oxidative abilities of the body and can effectively slow the progress of diseases such as PD [10].

Saussurea lappa is a oriental herbal medicine that has been used to improving asthma, inflammation, rheumatism, tuberculosis, and other diseases [11,12]. It has also been used as an analgesic, digestive, aphrodisiac, and diuretic [13]. Previous studies have shown that S. lappa extract possesses several pharmacological properties, such as anti-oxidative [14], anti-ulcer [11], anti-cancer [15], anti-viral [16], and hepatoprotective effects [13]. S. lappa extract was also found to decrease proinflammatory mediators in LPS-stimulated murine macrophage cells [17].

Although the health beneficial effects of olive fruit and leaf oils were confirmed in vitro using different cell lines, studies on the $S$. lappa extracts and their protective effect on neuroinflammatory conditions using microglial cells have not been demonstrated. In the present study the ethyl acetate fraction obtained from $S$. lappa Clarke (SLC-EA) was investigated for its anti-neuroinflammatory effects in LPS-stimulated
BV-2 microglial cells. Further the antioxidant property was also evaluated to substantiate its anti-neuroinflammatory effects.

\section{EXPERIMENTAL}

\section{Preparation of the Saussurea lappa extract}

S. lappa were purchased from the local market, Seoul, South Korea. To obtain the S. lappa extract, olives $(100 \mathrm{~g})$ were powdered in a mixer and washed three times with three volumes of ethanol. The residue of $S$. lappa (fruit pulp) was extracted with $1: 10$ ratio $(\mathrm{w} / \mathrm{v})$ of absolute ethanol $(\mathrm{EtOH})$ for $2 \mathrm{~h}$ in heating block at $70-80^{\circ} \mathrm{C}$. The ethanol extract of $S$. lappa obtained (the yield was $24.8 \%$ ) was resuspended in distilled water:EtOH (9:1, v/v) and separated sequentially with n-hexane, ethyl acetate (EA) and n-butanol to obtain a final production of 15.7, 43 and 21.5 $\%$, respectively. LPS-stimulated murine BV-2 microglial cells was investigated using SLC-EA extract. SLC-EA extract was dissolved in sterile distilled water, filtered on $0.22 \mu \mathrm{m}$ filters before use.

\section{DPPH radical scavenging activity}

The anti-oxidant activity of the SLC-EA extract was determined using the stable radical $\mathrm{DPPH}$ (2, 2-diphenyl-1-picrylhydrazyl, Sigma-Aldrich, St. Louis, MO, USA). The radical scavenging capacity was measured by using a reaction mixture set up by aliquots of the SLC-EA extract and a DPPH methanolic solution as described previously [19]. Briefly, a solution of $60 \mu \mathrm{L}$ of each SLC-EA extract, was added to $60 \mu \mathrm{L}$ of DPPH $(60 \mu \mathrm{M})$ in absolute methanol. After mixing strongly for $10 \mathrm{sec}$, the mixture was then moved into a $100 \mu \mathrm{L}$ Teflon capillary tube and the scavenging activity of each sample on DPPH radical was measured using a ESR spectrometer (Jeol Ltd, Tokyo, Japan). A spin adduct was measured by ESR spectrometer after 2 min.

\section{Cell culture and viability assay}

BV-2 microglia cells were cultured at $37^{\circ} \mathrm{C}$ in 5 $\% \mathrm{CO}_{2}$ in Dulbecco's Modified Eagle's Medium (DMEM, Invitrogen, Carlsbad, CA, USA) supplemented with $5 \%$ Fetal Bovine Serum (FBS, Hyclone, Logan, UT, USA) and the antibiotics penicillin and streptomycin purchased Invitrogen. In all experiments, murine BV-2 cells were pre-treated with the indicated concentrations of SLC-EA for $1 \mathrm{~h}$ before the addition of $1 \mu \mathrm{g} / \mathrm{mL}$ of LPS in DMEM alone.

For viability assay, MTT assay was used as described previously [20].

Trop J Pharm Res, September 2020; 19(9): 1912 


\section{Immunoblot analysis and antibodies}

Cultured cells were washed in cold PBS three times and lysed by lysis buffer $(50 \mathrm{mM}$ Tris- $\mathrm{HCl}$, $\mathrm{pH}$ 7.4, $1 \%$ (v/v) NP-40, $0.25 \%$ sodium deoxycholate, $150 \mathrm{mM} \mathrm{NaCl}, 1 \mathrm{mM}$ EDTA, 25 $\left.\mathrm{mM} \mathrm{NaF}, 2 \mathrm{mM} \mathrm{Na}_{3} \mathrm{VO}_{4}\right)$ and added protease inhibitor cocktail (Complete Mini ${ }^{\mathrm{TM}}$, Roche, Mannheim, Germany) at $4^{\circ} \mathrm{C}$. The lysate was cleared by centrifugation at $10,000 \times g$ for $20 \mathrm{~min}$ at $4^{\circ} \mathrm{C}$ to remove the residue of cell pellets [20]. Cell lysates were used for protein content using BCA reagent (Pierce, Rockford, IL, USA). Equal amounts of cellular protein were loaded onto 10 $\%$ sodium dodecyl sulfate-polyacrylamide gel electrophoresis (SDS-PAGE). Cellular proteins were transferred to a nitrocellulose membrain (NC) membrane (S\&S, Dassel, Germany) and blocked with $5 \%$ bovine serum albumin in trisbuffered saline (TBS, 50 mM Tris-Cl, pH 7.5. 150 $\mathrm{mM} \mathrm{NaCl}$ [ [20]. To detect protein expression, the blots were probed with the targeted antibodies against iNOS and TNF-a followed by the secondary antibodies coupled to horseradish peroxidase-conjugated secondary antibody (BioRad, Herculus, CA, USA). The detection of $\beta$ actin protein was used for an internal control protein. The immunoreactive proteins on the NC membrane were detected by chemiluminescence by ECL detection (Amersham Pharmacia Biotech, Piscataway, NJ) on X-ray film. The antibodies against iNOS, TNF- $\alpha$ and $\beta$-actin were purchased from Cell Signaling Technology INC. (Beverly, MA, USA).

\section{NO assay}

Production of nitric acid (NO) was measured the levels of nitrite in the cultured murine BV-2 cell supernatant using colorimetric assay with Griess reagent $\quad((0.1 \% \quad(\mathrm{w} / \mathrm{v}) \mathrm{N}-(1-$-naphathyl)ethylenediamine and $1 \%(\mathrm{w} / \mathrm{v})$ sulfanilamide in $5 \%(\mathrm{v} / \mathrm{v})$ phosphoric acid) [21]. Briefly, murine BV-2 cells $\left(2 \times 10^{5}\right.$ cells $\left./ \mathrm{mL}\right)$ were seeded in 6well plates in $0.5 \mathrm{~mL}$ complete DMEM medium and treated with the SLC-EA extract at indicated concentrations for $1 \mathrm{~h}$ and stimulated with 1 $\mu \mathrm{g} / \mathrm{mL}$ of Lipopolysaccharides (LPS, SigmaAldrich, St. Louis, MO, USA ) () for 2 h. Cultured supernatant $(50 \mu \mathrm{L})$ was reacted with an equal amount of Griess reagent. [20]. The absorbance was determined at $540 \mathrm{~nm}$ using a microplate reader (Tecan, Männedorf, Switzerland).

\section{TNF- $\alpha$ assay}

Murine BV-2 microglia cells $\left(1 \times 10^{5}\right.$ cells/well) were cultured on a flat form of 96 well plates and treated with the SLC-EA extract at indicated concentrations for $1 \mathrm{~h}$ and stimulated with 1 $\mu \mathrm{g} / \mathrm{mL}$ of LPS. At $4 \mathrm{~h}$ of post LPS treatment, the cells were harvested and the supernatants were subjected to evaluate tumor necrosis factor -- $\alpha$ (TNF- $\alpha$ ) levels using murine TNF- $\alpha$ ELISA kit from BD Biosciences (San Jose, CA, USA).

\section{Statistical analysis}

All data are presented as mean \pm SEM. Statistical significance ( $p<0.05$ for all analyses) was assessed by ANOVA using Instat 3.05 (GraphPad, San Diego, CA), followed by Student-Newman-Keuls analysis.

\section{RESULTS}

\section{Effect of SLC-EA extract on DPPH radical scavenging activity}

The capacity of SLC-EA to scavenge DPPH was measured by electron spin resonance (ESR) spectroscopy. As shown in Figure 1 A, SLC-EA showed significant DPPH radical scavenging activity in a dose-dependent manner presenting a maximum effect at $100 \mu \mathrm{g} / \mathrm{mL}$ of concentration $(p<0.001)$. The ESR spectroscopy data showed in Figure $1 \mathrm{~B}$.

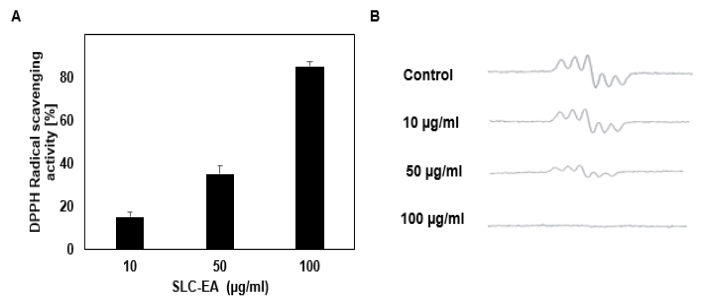

Figure 1: Effect of SLC-EA extract on DPPH radical scavenging activity. The capacity to scavenge the free radical DPPH by different concentrations of SLC-EA extract (A) and ESR spectra (B). BV-2 cells were treated with or without SLC-EA extract at the various concentrations $(10,50$ and $100 \mu \mathrm{g} / \mathrm{mL})$. The scavenging activity of each sample on DPPH radical was measured using a JES-FA electron spin resonance (ESR) spectrometer. A spin adduct was measured by ESR spectrometer accurately $2 \mathrm{~min}$ later. Data are showed as mean $\pm \operatorname{SEM}(n=3)$ for three independent experiments; ${ }^{*} p<0.05$ and ${ }^{* * *} p<$ 0.001 , compared with control group by Student t-test. SLC-EA = Saussurea lappa-ethyl acetate

\section{Effect of SLC-EA on BV-2 cell viability}

The cytotoxicity of SLC-EA extract was evaluated based on their effects on cell growth using MTT assay (> $95 \%$ cell viability). As shown in Figure 2 , treatment with SLC-EA at concentrations ranging from $10 \mu \mathrm{g} / \mathrm{mL}$ to $100 \mu \mathrm{g} / \mathrm{mL}$ did not affect cell viability nor did they exhibit any cytotoxicity in BV2 microglia (Figure 2). 


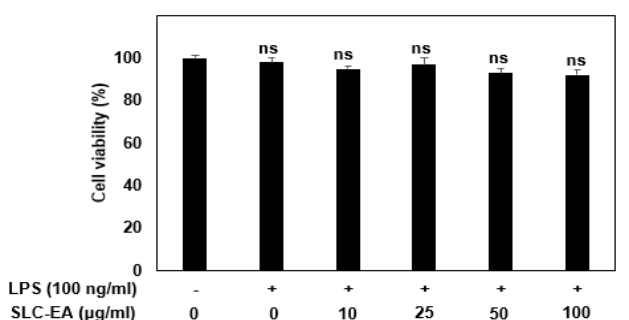

Figure 2: Effect of SLC-EA extract on the viability of BV-2 microglial cells. Cell viability in SLC-EA extract treated cells was determined using MTT assay in the presence or absence of LPS $(1 \mu \mathrm{g} / \mathrm{mL})$. The results showed in percentage of control samples. Data are presented as mean \pm SEM $(n=3)$ for three independent experiments. SLC-EA = Saussurea lappa-ethyl acetate

\section{SLC-EA extract reduces NO production in} LPS-stimulated murine BV-2 cells

In the next step, we examined the SLC-EA for its suppressive effects on NO release in LPSstimulated BV-2 microglia cells. As shown in Figure 3, LPS alone treated cells significantly increased the NO levels $(p<0.001)$. Pretreatment with SLC-EA extract significantly inhibited the LPS-stimulated increased NO release in BV-2 cells in a dosage dependent manner compared to LPS only treated cells. The maximum effect was observed at $100 \mu \mathrm{g} / \mathrm{mL}$ concentration $(p<0.001)$. The other concentrations of SLC-EA $(10,25$ and $50 \mu \mathrm{g} / \mathrm{mL})$ also significantly and dose-dependently inhibited the release of NO in LPS-stimulated BV-2 cells.

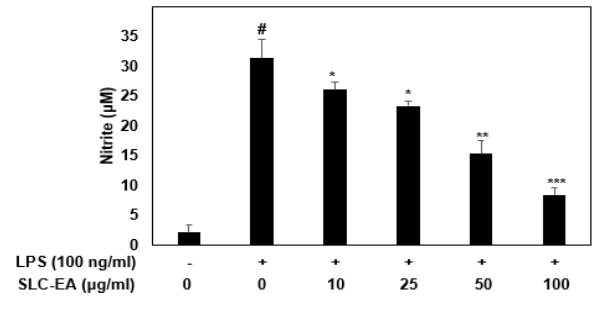

Figure 3: Effect of SLC-EA extract on NO Production in LPS-stimulated BV-2 microglial cells. BV-2 cells were treated with SLC-EA extract at various concentrations $(10,25,50$ and $100 \mu \mathrm{g} / \mathrm{mL})$ with or without $1 \mu \mathrm{g} / \mathrm{mL}$ of LPS for $4 \mathrm{~h}$. The nitrite in the murine BV-2 cell culture supernatant was evaluated using Griess reagent. Data are showed as mean \pm SEM $(\mathrm{n}=3)$ for three independent experiments; ${ }^{\#} p<$ 0.001 , when compared with control group; ${ }^{* *} p<0.01$ and ${ }^{* * *} p<0.001$, when compared with LPS alone treated group by Student t-test. SLC-EA = Saussurea lappa-ethyl acetate
SLC-EA extract reduces iNOS expression in LPS-stimulated murine BV-2 cells

Immuno- blot analysis showed that the protein expression of Inducible nitric oxide synthase (iNOS) in the LPS-stimulated murine BV-2 cells was also suppressed in a concentrationdependent manner (Figure 4). Although LPSstimulated BV-2 cells are associated with the increased iNOS expression, pretreatment with SLC-EA extract suppressed the increased iNOS protein expressional levels.

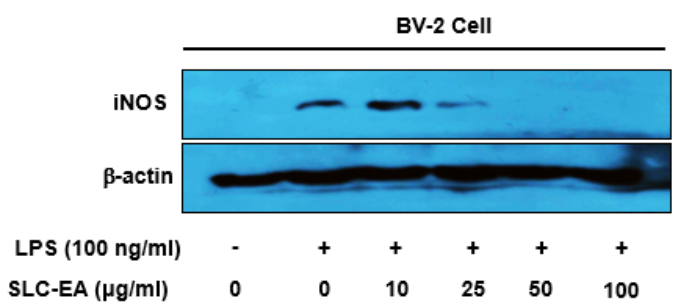

Figure 4: Effect of SLC-EA extract on iNOS expression in LPS-stimulated murine BV-2 microglial cells. The iNOS protein expression in the LPSstimulated murine BV-2 cells by various concentration of the SLC-EA extract was used by immune-blot analyses with the targeted antibodies against iNOS. The internal control used was $\beta$-actin. SLC-EA = Saussurea lappa-ethyl acetate

\section{Effect of SLC-EA extract on TNF-a production in LPS-stimulated BV-2 cells}

The suppressive effect of SLC-EA on the expression of tumor necrosis factor- $\alpha$ (TNF- $\alpha$ ) in protein levels was also confirmed by Immunoblot analysis using a targeted antibody against murine TNF- $\alpha$. Murine BV-2 cell culture supernatant was harvested $4 \mathrm{~h}$ after administrating LPS for analysis of TNF- $\alpha$ production by enzyme-linked immunosorbent assay (ELISA). As shown Figure 5, the level of TNF- $\alpha$ increased significantly after LPS treatment when compared to those in untreated cells. However, the SLC-EA extract at indicated concentrations $(10,20,40$ and $80 \mu \mathrm{g} / \mathrm{mL})$ significantly inhibited TNF- $\alpha$ production in a dose- dependent manner.

The SLC-EA extracted sample was filtered through a $0.45 \mu \mathrm{m}$ poly syringe-tip filter. the sample was analyzed using a reversed-phase HPLC system (Agilent 1200, MA, USA), a quaternary pump, and a vacuum degasser. For HPLC analyses of quercetin contents in the SLCEA, a ZORBAX C18 column (XDB-C18, 4.6×150 $\mathrm{mm}, 5 \mu \mathrm{m}$ ) was used. Two mobile phases were used: solvent A, $5 \%$ acetic acid; B, $100 \%$ acetonitrile. 


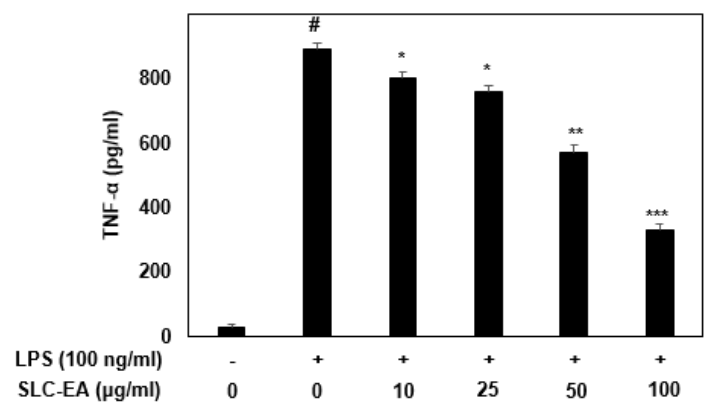

Figure 5: Effect of SLC-EA extract on TNF- $\alpha$ production in LPS-stimulated murine BV-2 microglial cells. Suppression of pro-inflammatory cytokine TNF- $\alpha$ expression by SLC-EA extract was measured with ELISA test. BV-2 cells were treated with SLC-EA extract at $10,25,50$ and $100 \mu \mathrm{g} / \mathrm{mL}$ with or without 1 $\mu \mathrm{g} / \mathrm{mL}$ of LPS for $4 \mathrm{~h}$. The TNF- $\alpha$ in the murine BV-2 cell culture supernatant was tested using a murine TNF- $\alpha$ ELISA kit. Data are showed as the mean \pm S.E.M. $(\mathrm{n}=3)$ for three independent experiments; ${ }^{*} p<$ 0.001 , when compared with control group; ${ }^{* *} p<0.01$ and ${ }^{* * *} p<0.001$, when compared with LPS alone group by Student t-test. SLC-EA = Saussurea lappaethyl acetate
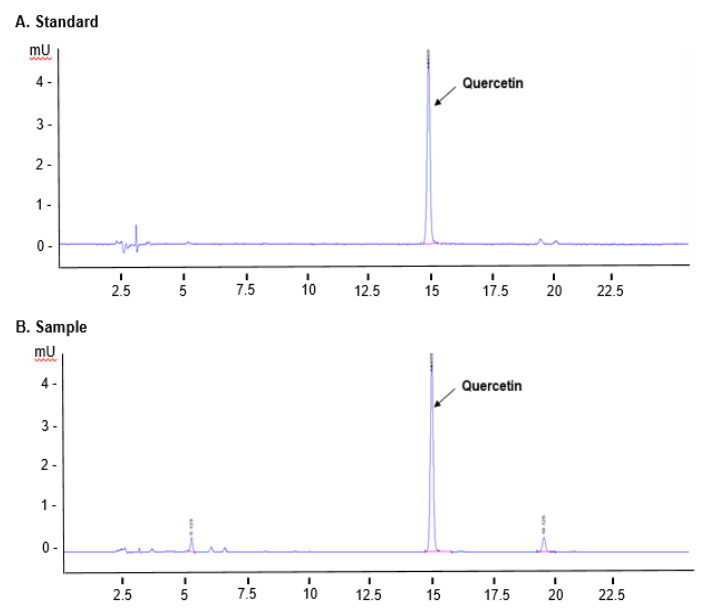

Figure 6: HPLC chromatograms of quercetin standard (A), SLC-EA extracts (B).

The analytical High-Performance Liquid Chromatography (HPLC) chromatograms of SLC-EA containing quercetin were presented in Figure 6. The calibration curves for the quercetin standards have been established. Content of quercetin in the SLC-EA was $6.103 \mu \mathrm{g} / \mathrm{mg}$.

\section{DISCUSSION}

In the present study, these results showed that the ethyl acetate fraction of Saussurea lappa extract significantly inhibited the increased production of $\mathrm{NO}$, suppressed the expression of iNOS protein level and attenuated the increased
TNF- a production and protein expression in LPS-simulated BV-2 microglial cells. Further the SLC-EA extract significantly scavenged the DPPH free radicals.

Previous studies have been demonstrated to identify the various diseases, and to understand the physiological role involved in the cell death of dopaminergic neuronal cell in order to ascertain the mechanisms of conventional and novel agents performing through anti-oxidative and anti-apoptotic mechanisms [21]. Stimulation of neuronal cell death involving oxidative stress and mitochondrial dysfunction are the key known neurodegenerative processes in PD [22]. Therefore, inhibition of death of dopaminergic neuronal cell by adaptable intracellular reactive oxygen species (ROS) and modifying the apoptotic pathway may have therapeutic value, which may lead to mitigation of the progression of neurodegeneration.

Thus, free radicals are important mediators that provoke or sustain inflammatory responses and their neutralization by antioxidants and radical scavengers can reduce neuroinflammation. It was well known that DPPH radical assay is one of the generally used methods for calculating the free radical scavenging activities of antioxidants [23].

The beneficial effects of polyphenolic compounds are directly related to the radical scavenging capability with the formation of less-reactive flavonoid phenoxyl radicals. In our present study, the ethyl acetate fraction obtained from the Olive fruit pulp extract also exhibited significant free radical scavenging effect indicating that the fruit pulp extract also contained potential antioxidant agents.

In light of existing reports that antioxidants can reduce neuroinflammation, we used SLC-EA extract to study for its anti-neuroinflammatory activity in LPS-stimulated BV-2 cells. Significant reports now exist that inflammatory mediators such as NO and iNOS are responsible for the symptoms of various neuroinflammatory diseases. Furthermore, the neuroinflammatory response was represented by stimulated microglia, producing elevated levels of proinflammatory cytokines. Thus, suppression of cytokine production or function serves as a key role in the control of inflammatory responses in neurodegeneration. The present results that the SLC-EA extract significantly inhibited the increased NO production and iNOS protein expression in LPS-stimulated murine BV-2 cells.

Trop J Pharm Res, September 2020; 19(9): 1915 
TNF-a, an inflammatory cytokine, mainly produced by activated macrophages is involved in systemic inflammation that stimulate the acute phase reaction. TNF- $\alpha$, not only amplifies the inflammatory cascade, but also causes the inflammatory injury. TNF- $\alpha$ expression was found to be upregulated in the brains of patients with neurodegenerative diseases such as $A D$ and $P D$ suggesting a causative role in neurodegenerative disorders [24,25]. Oxidative stress could induce neuronal damage in Parkinsonian brain, and modulate intracellular signaling, ultimately leading to neuronal cell death by apoptosis or necrosis [26]. Generation of ROS causes severe damage of cellular functions affecting the apoptotic pathway and is suggested to play an important role in the development of neurodegenerative disorders [27]. From these results, we could affirm that SLC-EA acts by suppressing TNF- $\alpha$ and thereby inhibiting the NO and iNOS expressional levels in LPS-stimulated BV-2 cells, which are involved in the neuroinflammatory events. Previous studies have shown that SLC contains a large amount of two main sesquiterpene lactones, costunolide (CTL) and dehydrocostus lactone (DTL) [12]12]. This study showed quantitative HPLC chromatograms of SLC-EA containing quercetin were presented in Figure 6. From this results, SLC ethyl acetate extract contains more polyphenols.

\section{CONCLUSION}

This study demonstrates a significant role of SLC-EA in mitigating neuroinflammatory responses in LPS-stimulated BV-2 microglial cells. The SLC-EA extract also showed potent antioxidant effects and could be developed as a potential therapeutic herbal medicine for improving neurodegenerative diseases.

\section{DECLARATIONS}

\section{Acknowledgement}

This study was supported by Research Fund of Dankook University in 2018.

\section{Conflict of interest}

No conflict of interest is associated with this work.

\section{Contribution of authors}

We declare that this work was done by the authors named in this article and all liabilities pertaining to claims relating to the content of this article will be borne by the authors.

\section{Open Access}

This is an Open Access article that uses a funding model which does not charge readers or their institutions for access and distributed under the terms of the Creative Commons Attribution License (http://creativecommons.org/licenses/by/ 4.0) and the Budapest Open Access Initiative (http://www.budapestopenaccessinitiative.org/rea d), which permit unrestricted use, distribution, and reproduction in any medium, provided the original work is properly credited.

\section{REFERENCES}

1. Pettmann B, Henderson CE. Neuronal cell death. Neuron 1998; 20: 633-647.

2. Pieczenik SR, Neustadt J. Mitochondrial dysfunction and molecular pathways of disease. Exp Mol Pathol 2007; 83: 84-92.

3. Szeto HH. Mitochondria-targeted peptide antioxidants: novel neuroprotective agents. The AAPS J 2006; 8: 521-531.

4. Mattson MP. Apoptosis in neurodegenerative disorders. Nature reviews. Mol Cell Biol 2000; 1: 120-129.

5. Nelson PT, Soma LA, Lavi E. Microglia in diseases of the central nervous system. Annul Med 2002; 34: 491-500.

6. Eikelenboom $P$, van Gool WA. Neuroinflammatory perspectives on the two faces of Alzheimer's disease. $J$ Neural Transm 2004; 111: 281-294.

7. Dawson MR, Dobbs A, Hooper HR, McEwan AJ, Triscott $J$, Cooney J. Artificial neural networks that use singlephoton emission tomography to identify patients with probable Alzheimer's disease. Euro J Nucl Med 1994; 21: 1303-1311.

8. Van Kampen J, RobertsonH, Hagg $T$, Drobitch $R$. Neuroprotective actions of the ginseng extract G115 in two rodent models of Parkinson's disease. Exp Neurol 2003; 184: 521-529.

9. Levites Y, Weinreb O, Maor G, Youdim MB, Mandel S. Green teapolyphenol (-)-epigallocatechin-3-gallate prevents N-methyl-4-phenyl-1,2,3,6tetrahydropyridineinduced dopaminergic neurodegeneration. J Neurochem 2001; 78: 10731082.

10. Todorov IN, Zaikov GE, Degterev IA. Bioactive compounds: Biotransformation of Biological Action, Mechanism of antistress and anabolic action of Eleutherococcus, Nova Science Publishers, Inc: Commack, NY, 2003; 26-27.

11. Shah NC. Herbal folk medicines in Northern India. J Ethnopharmacol 1982; 6: 293-301.

12. Choi HG, Lee DS, Li B, Choi YH, Lee SH, Kim YC. Santamarin, a sesquiterpene lactone isolated from Saussurea lappa, represses LPS induced inflammatory

Trop J Pharm Res, September 2020; 19(9): 1916 
responses via expression of heme oxygenase-1 in murine macrophage cells. Int Immunopharmacol 2012; 13: $271-279$.

13. Yaeesh S, Jamal Q, Shah AJ, Gilani AH. Antihepatotoxic activity of Saussurea lappa extract on D-galactosamine and lipopolysaccharide-induced hepatitis in mice. Phytother Res 2010; 24: 229-232.

14. Saleem TS, Lokanath N, Prasanthi A, Madhavi M, Mallika G, Vishnu MN. Aqueous extract of Saussurea lappa root ameliorate oxidative myocardial injury induced by isoproterenol in rats. J Adv Pharm Technol Res 2013; 4: 94-100.

15. Kim EJ, Hong JE, Lim SS, Kwon GT, Kim J, Kim JS, Lee $K W$, Park JH. The hexane extract of Saussurea lappa and its active principle, dehydrocostus lactone, inhibit prostate cancer cell migration. J Med Food 2012; 15: 24-32.

16. Chen HC, Chou CK, Lee SD, Wang JC, Yeh SF. Active compounds from Saussurea lappa Clarks that suppress hepatitis $B$ virus surface antigen gene expression in human hepatoma cells. Antivir Res 1995; 27: 99-109.

17. Choi HG, Lee DS, Li B, Choi YH, Lee S, Kim YC. Santamarin, a sesquiterpene lactone isolated from Saussurea lappa, represses LPS induced inflammatory responses via expression of heme oxygenase-1 in murine macrophage cells. Int Immunopharmacol 2012; 13: 271-279

18. Sarwar A, Enbergs $H$. Effects of Saussurea lappa roots extract in ethanol on leukocyte phagocytic activity, lymphocyte proliferation and interferongamma (IFNgamma). Pak J Pharm Sci 2007; 20: 175-179.

19. Sanches-Moreno C, Plaza L, Ancos B, Cano MP. Nutritional characterization of commercial traditional pasteurized tomato juices: carotenoids, vitamin and radical-scavenging activity. Food Chem 2006; 98: 749756.

20. Tang YJ, Yang JS, Lin CF, Shyu WC, Tsuzuki M, Lu CC, Chen YF, Lai KC. Houttuynia cordata Thumb extract induces apoptosis through mitochondrial-dependent pathway in HT-29 human colon adenocarcinoma cells. Oncol Rep 2009; 22: 1051-1056.

21. Green LC, Wagner DA, Glogowski J, Skipper PL, Wishnok JS, Tannenbaum SR. Analysis of nitrate, nitrite, and $[15 N]$ nitrite in biological fluids. Anal Biochem. 1982; 126: 131-138.

22. Fiskum G, Starkov A, Polster BM, Chinopoulos C. Mitochondrial mechanisms of neural cell death and neuroprotective interventions in Parkinson's disease. Ann Ny Acad Sci 2013; 991: 111-119.

23. Sachindra NM, Sato E, Maeda $H$, Hosokawa M, Niwano Y, Kohno M, Miyashita K. Radical scavenging and singlet oxygen quenching activity of marine carotenoid fucoxanthin and its metabolites. J Agric Food Chem 2007; 55: 8516- 8522.

24. Perry RT, Collins JS, Wiener H, Acton R, Go RC. The role of TNF and its receptors in Alzheimer's disease. Neurobiol Aging 2001; 22: 873-883.

25. Nagatsu $T$, Sawada $M$. Inflammatory process in Parkinson's disease: Role for cytokines. Curr Pharm Des 2005; 11: 999-1016.

26. Mohr E, Mendis T, Grimes JD. Late cognitive changes in Parkinson's disease with an emphasis on dementia. Adv in Neurol 1995; 65: 97-113.

27. Kehrer JP, Smith CV. Free radicals in biology: sources, reactivities, and roles in the etiology of human diseases. San Diego: Academic Press. 1994; 25-62. 